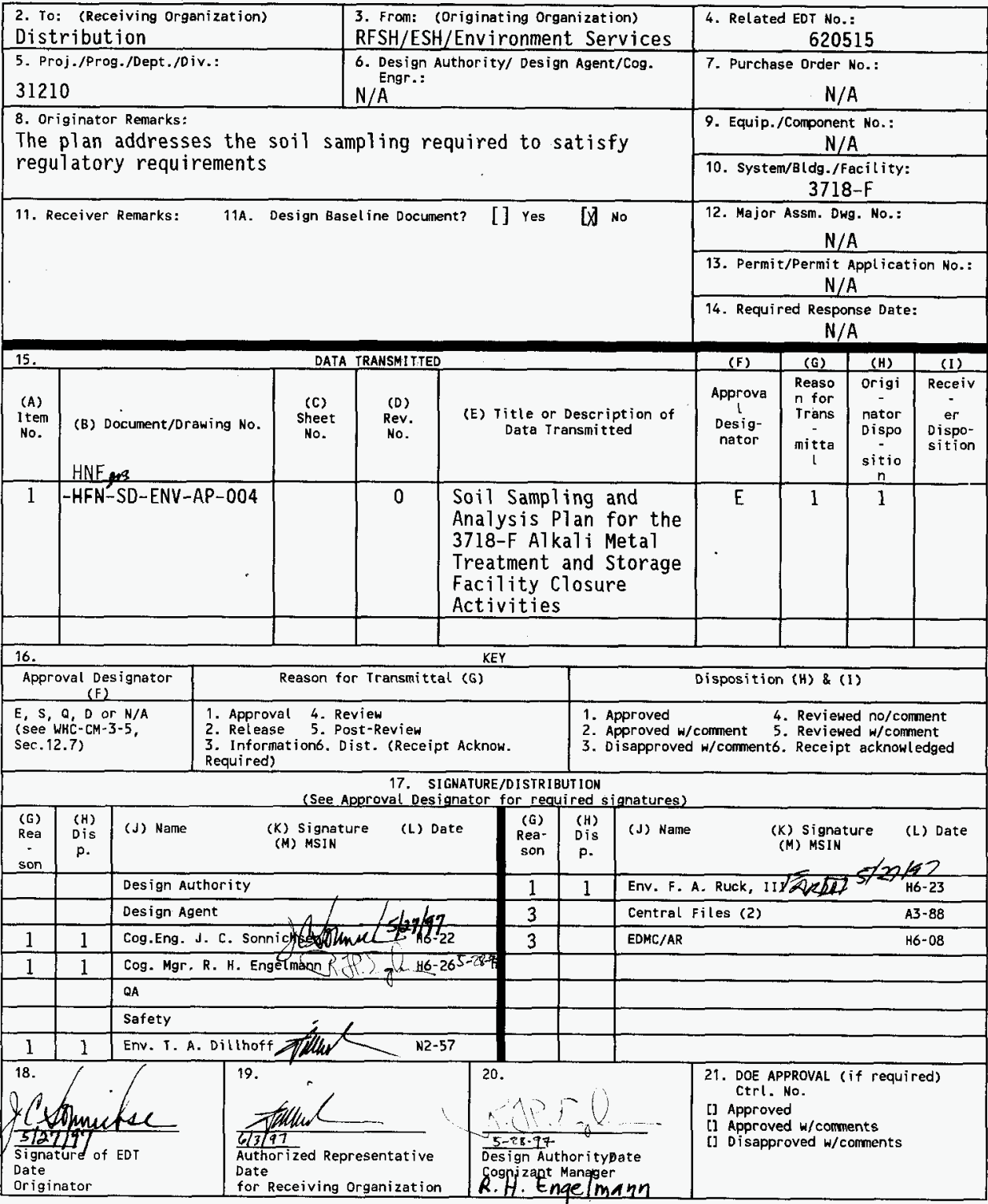




\section{Soil Sampling and Analysis Plan for the 3718-F Alkali Metal Treatment and Storage Facility Closure Activities}

J. C. Sonnichsen, Jr.

Rust Federal Services of Hanford Co., Richland, WA 99352

U.S. Department of Energy Contract DE-AC06-96RL13200

$\begin{array}{lll}\text { EDT/ECN: } & 6157285 \mathrm{I} & \text { UC: } 630 \\ \text { Org Code: } & 31210 & \text { Charge Code: } \\ \text { B\&R Code: } & \text { EX7050000 } & \text { Total Pages: } 44\end{array}$

Key Words: Dangerous Waste, Sampling, Analysis, Soils, Cleanup Levels, Field Work

Abstract: The plan defines the soil sampling and analysis to be performed at the 3718-F TSD to satisfy the Hanford Facility RCRA Permit Conditions.

TRADEMARK DISCLAIMER. Reference herein to any specific commercial product, process, or service by trade name, trademark, manufacturer, or otherwise, does not necessarily constitute or imply its endorsement, recommendation, or favoring by the United stetes Goverment or any agency thereof or its contractors or subcontractors.

Printed in the United States of America. To obtain copies of this document, contact: WHC/BCS Document Control Services, P.O. Box 1970, Mailstop H6-08, Richland WA 99352, Phone (509) 372-2420; Fax (509) 376-4989.
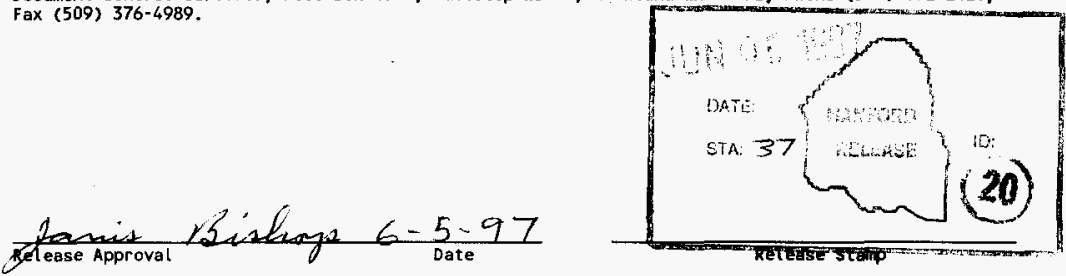

\section{Approved for Public Release}




$$
\text { HNF-SD-ENV-AP-004, Rev. } 0
$$

SOIL SAMPLING AND ANALYSIS PLAN FOR THE 3718-F ALKALI METAL TREATMENT AND STORAGE FACILITY CLOSURE ACTIVITIES 


\section{CONTENTS}

1.0 PURPOSE . . . . . . . . . . . . . . . . . . . . . . . . 1

2.0 BACKGROUND: SITE DESCRIPTION AND STATUS . . . . . . . . . . . . 1

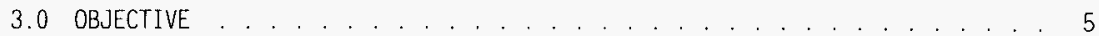

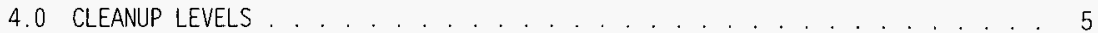

5.0 FIELD WORK . . . . . . . . . . . . . . . . . . 7

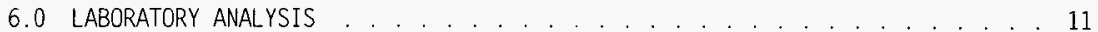

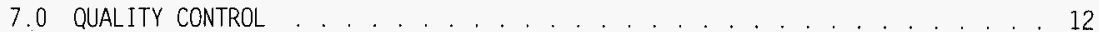

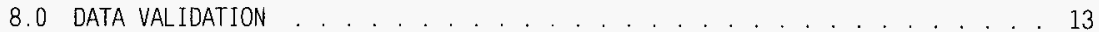

9.0 PATH FORWARD . . . . . . . . . . . . . . . . . . . . 14

10.0 REFERENCES . . . . . . . . . . . . . . . . . . . 15

\section{FIGURES}

1. Map of 300 Area Showing Location of 3718-F Facility . . . . . . . . . 2

2. Treatment, Storage, and Disposal Boundary of the 3718-F Facility as Defined in the Part A. Form 3 Permit . . . . . . . . . . . . . . . . . . . 3

3. Soil Sampling Locations . . . . . . . . . . . . . . . . 9

\section{TABLES}

1. A Summary of Soil Sampling for Inorganics . . . . . . . . . . . . . . . 11

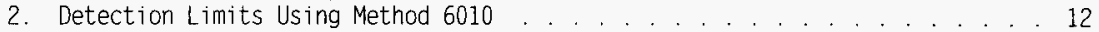


HNF-SD-ENV-AP-004, Rev. 0

8 Ecology

$9 \quad$ EII

$10 \quad$ ICP

11 IRIS

12 MDL

13 MTCA

$14 \quad \mathrm{NIOSH}$

15 RCRA

16 RTECS

17 TSD

18 WAC

\section{LIST OF TERMS}

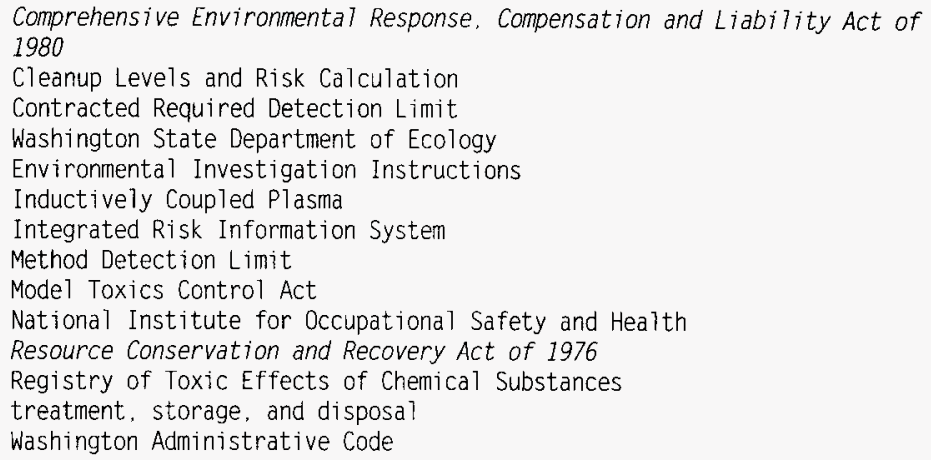


HNF-SD-ENV-AP-004, Rev. 0

\section{SOIL SAMPLING AND ANALYSIS PLAN FOR THE 3718-F ALKALI METAL TREATMENT AND STORAGE FACILITY CLOSURE ACTIVITIES}

\subsection{PURPOSE}

Amendment V.13.B.b to the approved closure plan (DOE-RL 1995a) requires that a soil sampling and analysis plan be prepared and submitted to the Washington State Department of Ecology (Ecology) for review and approval. Amendment V.13.B.C requires that a diagram of the 3718-F Alkai i Metal Treatment and Storage Facility unit (the treatment, storage, and disposal [TSD] unit) boundary that is to be closed, including the maximum extent of operation, be prepared and submitted as part of the soil sampling and analysis plan. This document describes the samping and analysis that is to be performed in response to these requirements and amends the closure plan. Specifically, this document supersedes Section 6.2, lines 43-46, and Section 7.3 .6 of the closure plan.

Results from the analysis will be compared to cleanup levels identified in the closure plan. These cleanup levels will be established using residential exposure assumptions in accordance with the Model Toxics Control Act (MTCA) Cleanup Regulation (Washington Administrative Code [WAC] 173-340) as required in Amendment V.13.B.1. Results of all sampling, including the raw analytical data, a summary of analytical results, a data va?idation package, and a narrative summary with conclusions will be provided to Ecology as specified in Amendment V.13.B.e. The results and process used to collect and analyze the soil samples will be certified by a licensed professional engineer. These results and a certificate of closure for the balance of the TSD unit, as outlined in Chapter 7.0 of the approved closure plan (storage shed, concrete pad, burn building. scrubber, and reaction tanks), will provide the basis for a closure determination.

\subsection{BACKGROUND: SITE DESCRIPTION AND STATUS}

The 3718-F Facility is located in the southeast quadrant of the 300 Area. The location of the TSD unit is shown in Figure 1. The TSD unit began treatment of alkali metal waste in 1968 and continued through June 1987. Storage activities began in 1968 and continued through May 1989. Equipment contaminated with sodium was cleaned using baths of either water, methanol, isopropanol, or 2-butoxy ethanol.

In accordance with Amendment V.13.B.C. Figure 2 provides a diagram of the TSD unit boundary to be closed. The area to be closed includes the buildings and treatment tanks that are located on the concrete pad, the concrete pad, and the surrounding soi 1 within 3 meters of the concrete pad (see Figure 2). The maximum extent of normal operation extended to the edge of the concrete pad, as described in 
HNF-SD-ENV-AP-004, Rev. 0

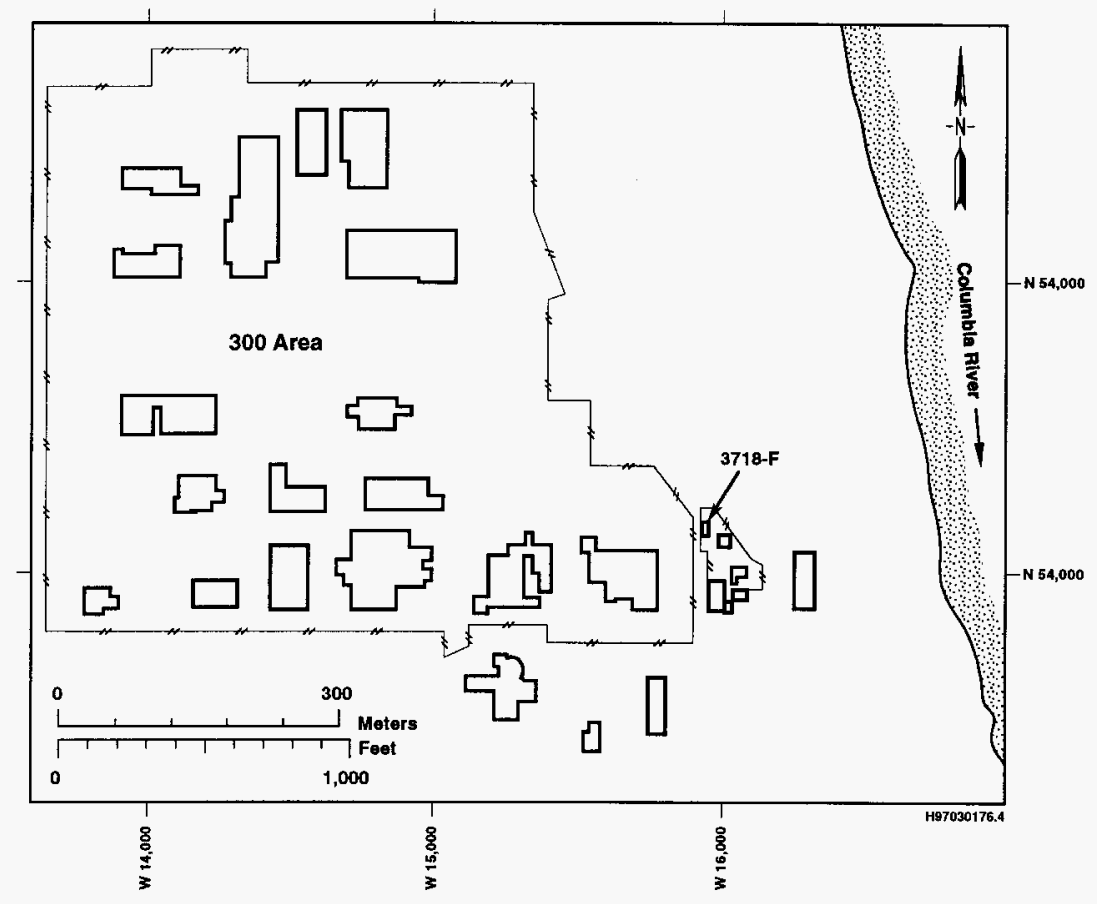

1 Figure 1. Map of 300 Area Showing Location of 3718-F Faci7ity. 


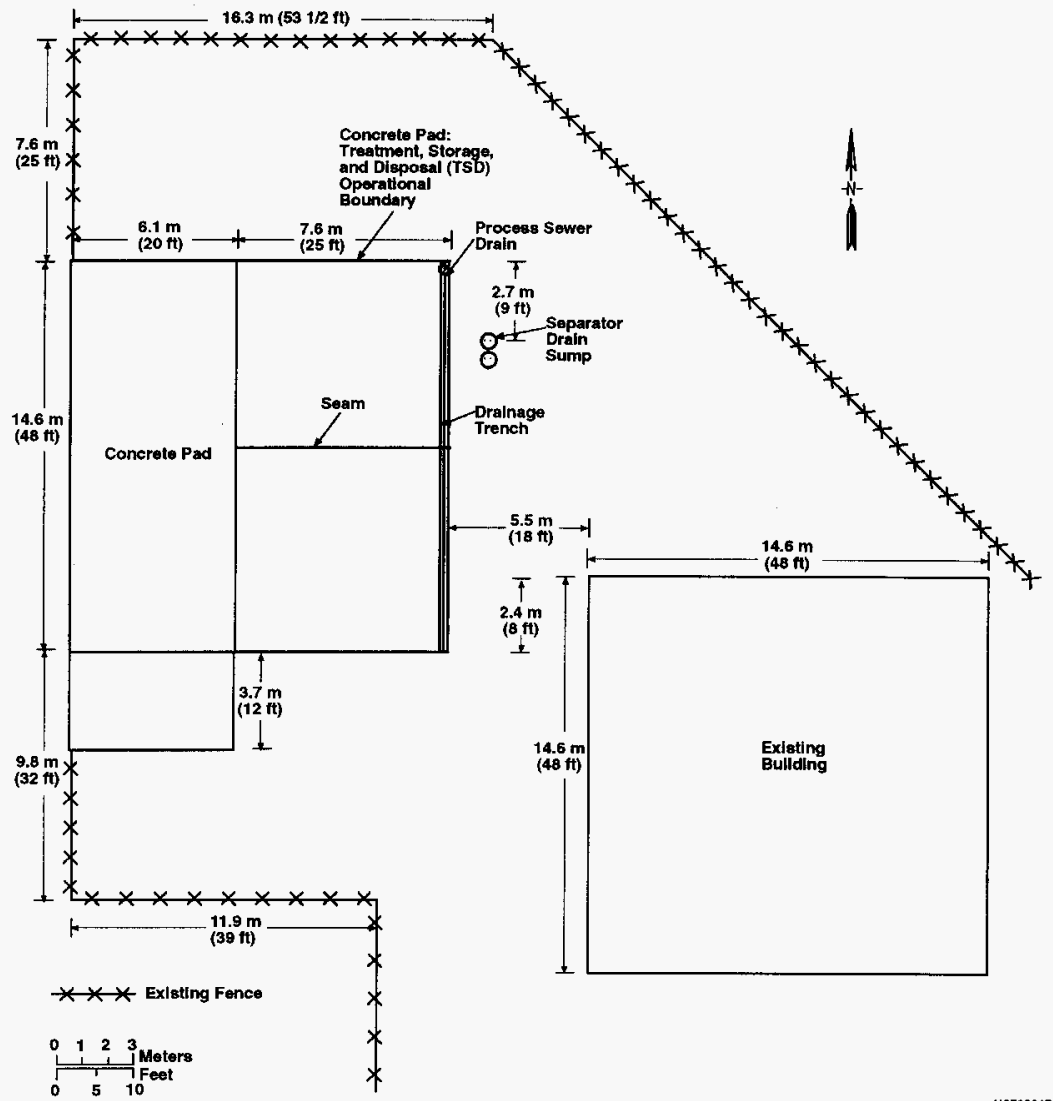

H97030176.2

1 Figure 2. Treatment, Storage, and Disposal Boundary of the 3718-F Facility as

2 Defined in the Part A, Form 3 Permit. 
the Part A. Form 3, "3718-F Alkali Metal Treatment and Storage Area." Rev. 4 (DOE-RL 1988). It has been assumed that some spillage or unintentional release of product or waste (used cleaning reagent) may have flowed to the soil along the east side of the concrete pad.

Three stainless stee? tanks were used to treat laboratory-scale components. A1 1 components treated at the TSD unit had been placed in a flowing liquid alkali metal (sodium, lithium, potassium) environment before treatment. In most cases, this was a liquid sodium environment. When the sodium was drained or allowed to cool, some of the alkali metal adhered to the surface of the stainless steel. The alkali metal, most often sodium, was removed from these components using an alcohol bath in the stainless steel tanks or reaction vessels at the TSD unit. The components were cleaned by immersion in one of several alcohols, such as methanol. isopropano1, or 2-butoxy ethanol (Dowano1). Dowanol was most commonly used because the reaction rate with sodium is slower than the reaction rate with lighter alcohols and water. The majority of components that were treated in the steel tanks were fabricated from stainless steel. Some of the components may have been fabricated from carbon steel. The components consisted of piping, valves, sealed instruments, and sealed electromagnetic pumps. The reaction process (treatment or cleaning) typically would take several days depending on the amount of sodium coated on the component, the presence of tight crevices, and the strength of the cleaning agent (Dowanol). The final step of the cleaning process consisted of a water bath in a separate tank.

From a chemistry perspective, alcohol and water are used commonly by industry to remove sodium from stainless steel. The reaction process with alcohol produces alkoxides and hydrogen. Although these alkoxides are strong bases, they are not concentrated sufficiently to cause any damage to the steel during the reaction process. The reaction of water with sodium produces sodium hydroxide and hydrogen. The sodium hydroxide produced in the reaction process is not sufficiently caustic to cause measurable corrosion of the stainless steel. Therefore. the reaction in the treatment tanks most likely did not result of the release of nickel or chromium. Visual inspection of the remaining stainless steel tank at the TSD unit showed no evidence of pitting, corrosion, or oxidation. All alkali metal byproducts eventualiy will form a carbonate when exposed to environmental media (soil, air, and water).

Periodically, the used cleaning reagents (water and alcohols) were replaced or replenished. Before 1985, these solutions were drained onto the concrete pad through a valve in the bottom of the tanks. The concrete pad sloped toward a trough that was located along the east side of the pad. The spent reagent would flow across the pad to the trough and from the trough to the 300 Area Process Sewer. Beginning in 1985, a 11 spent alcohol solutions were packaged in approved containers and handled as dangerous waste. The used water continued to be drained to the process sewer. The TSD unit ceased treatment in 1987. 
Clean closure of the buildings and treatment tanks has been completed. Closure of these components followed the process outlined in Chapter 7.0 of the approved closure plan. A certificate of closure for these components has been received from a licensed professional engineer and placed in the Administrative Record. The characterization of the soil remains and is the subject of this sampling and analysis plan. As stated previously, the results and process that will be used to plan, collect, and analyze soil samples will be certified by an independent licensed professional engineer. These two certifications along with the results from the soil sampling and analysis will provide the basis for a closure determination.

\subsection{CLEANUP LEVELS}

In this section, soil cleanup levels are quantified for the three dangerous waste constituents identified in the approved closure plan (DOE-RL 1995a). The dangerous waste constituents include: sodium carbonate, 1ithium carbonate, and potassium carbonate. The cleanup levels were established in accordance with the residential exposure requirements provided in MTCA (WAC 173-340) Methods A or B (see Amendment V.13.B.1) or the use of a natural background concentration as specified in WAC 173-340-700(4)(d). Because soil cleanup levels have not been tabulated for all of the dangerous waste constituents (Method A). cleanup levels were assigned using either the natural background concentration. where appropriate. or the Method $B$ guidelines.

The continual wetting and drying of sediments under the natural environmental conditions of the Hanford Site has resulted in the gradual increase of carbonates in the first few meters of the vadose zone. As a result. sediments across the Hanford Site contain significant amounts of carbonates. 
HNF-SD-ENV-AP-004, Rev. 0

\subsection{SODIUM CARBONATE}

In support of environmental restoration activities, a study was performed to establish the naturally occurring background concentrations for most nonradioactive analytes that reside in the Hanford Soils (DOE-RL 1995b). The chemical composition of over 170 soil samples from 22 locations on the Hanford Site and 3 locations adjoining the Hanford Site were used as a basis to establish the natural background concentrations. For sodium, the concentration ranged from 98.7 milligrams of metal per kilogram of $50 i 1(\mathrm{mg} / \mathrm{kg})$ to $6,060 \mathrm{mg} / \mathrm{kg}$. The mean concentration for the sodium analyte was calculated to be $480 \mathrm{mg} / \mathrm{kg}$.

Using the statistical guidance provided in WAC 173-340-708(11)(d) of MTCA. a representative sitewide background concentration of $1.390 \mathrm{mg} / \mathrm{kg}$ for sodium was calculated for the 95 percent confidence interval for the 95 th percentile (i.e. coverage of 95 percent and a tolerance coefficient of 95 percent). (See Chapter 6.0. Section 6.3.2.3 [DOE-RL 1995b]).

A soil cleanup level for sodium has not been tabulated in the "Model Toxics Control Act Cleanup Levels and Risk Calculation (CLARC)" document (Ecology 1996). A reference dose for sodium carbonate was not found in the Integrated Risk Information System (IRIS). Furthermore, little information on risk to human health from exposure to this constituent was found in the literature. As a point of reference, the $L_{50}$ for rat (oral) was found in the National Institute for Occupational Safety and Health (NIOSH) Registry of Toxic Effects of Chemical Substances (RTECS) database to be $4,090 \mathrm{mg} / \mathrm{kg}$ or toxic category 0 .

Following the MTCA guidance (selection of the most stringent condition), a soil cleanup level of $1390 \mathrm{mg} / \mathrm{kg}$ is assigned to sodium.

\subsection{LITHIUM CARBONATE}

As discussed in the two previous sections, carbonates are abundant in the soil at the Hanford Site. A soil cleanup level for lithium was established using the same process outlined for sodium. Using the sitewide background concentration data (DOE-RL 1995b), the concentration for lithium was measured from 68 samples, which established a range from $34 \mathrm{mg} / \mathrm{kg}$ to $38 \mathrm{mg} / \mathrm{kg}$. The mean was calculated to be 34.1 $\mathrm{mg} / \mathrm{kg}$. Using the tolerance interval approach. a soil cleanup level of $37 \mathrm{mg} / \mathrm{kg}$ was assigned to lithium.

Lithium carbonate is used for the treatment of some psychological disorders. The NIOSH RTECS database states that daily dosages of $1.200 \mathrm{mg}$ to $1.800 \mathrm{mg}$ have been used without serious side effects. The $L_{50}$ for rat (oral) was found in the NIOSH RTECS database to be $525 \mathrm{mg} / \mathrm{kg}$ or toxic category $\mathrm{D}$.

Following the MTCA guidance, a soil cleanup level of $37 \mathrm{mg} / \mathrm{kg}$ is assigned to lithium. This cleanup level is well below the health hazard as determined by the NIOSH RTECS database. 
HNF-SD-ENV-AP-004, Rev. 0

\subsection{POTASSIUM CARBONATE}

A soil cleanup level for potassium was established using the same process outlined for both lithium and sodium. The background concentration for potassium was measured from 117 samples, which established a range from $851 \mathrm{mg} / \mathrm{kg}$ to $3,780 \mathrm{mg} / \mathrm{kg}$. The mean was calculated to be $1,414 \mathrm{mg} / \mathrm{kg}$. Using the tolerance interval approach, a soil cleanup leve? of $3.090 \mathrm{mg} / \mathrm{kg}$ was assigned to potassium.

A reference dose for humans was not found in the IRIS database. The $L_{50}$ for rat (oral) was found to be $1.870 \mathrm{mg} / \mathrm{kg}$ or toxic category D (NIOSH RTECS).

Following the MTCA guideline, a soil cleanup level of $3,090 \mathrm{mg} / \mathrm{kg}$ is assigned to potassium.

\subsection{FIELD WORK}

A phased approach will be used to characterize the soil. Phase I will consist of collecting a limited number of soil samples to determine whether dangerous waste that had resulted from the operations of the TSD unit was released to the soil column. To complete this phase, soil samples will be collected from three locations representative of worst-case contamination pathways. If these samples indicate that contaminants of concern are present above cleanup levels, the sampling and analysis plan will be revised to include a second phase of sampling, which would address the full nature and extent of soil contamination.

As currently planned, the field work will be performed by RUST Federal Services Northwest (RFS). Sampling and Mobile Laboratory (SML) personnel. The field work will be performed under the direction of RUST Federal Services of Hanford. Inc. (RFSH), Hanford Analytical Services Program, Sample Management Group (SMG). The SMG has the responsibility to coordinate all work performed in both the laboratory and the fieid. The coordination and control of these activities is administered through a Sample Authorization Form. The SMG will prepare and issue the Sample Authorization Form. This Sample and Analysis Plan will be used by the SMG to prepare the Sample Authorization Form.

\subsection{SAMPLING PROCEDURES}

The activities associated with implementing this sampling and analysis plan will be conducted in accordance with existing Environmental Investigation Instructions (EII) (WHC 1988) procedures as follows:

- EII 5.2, Soil and Sediment Sampling 
HNF-SD-ENV-AP-004, Rev. 0

1 - EII 1.1, Hazardous Worker Site Entry Requirements (graded approach and as

\subsection{PHASE I ANALYTES OF CONCERN}

As defined in the closure plan, the analytes of concern consist of the alkali metal carbonates (sodium carbonate, potassium carbonate, and lithium carbonate) and the alcohols used for cleaning (methanol, isopropanol. 2-butoxy ethanol). Sampling for the three alcohols is unnecessary because these chemicals breakdown extremely fast in the natural environment when exposed to sunlight and biological activities. The biological half-life for methanol is estimated to be 17.8 days. The biological half-life for both isopropanol and 2-butoxy ethanol is less than 24 hours. Therefore. for Phase I it was decided to focus all sampling and analysis activities towards the quantification of total sodium, total lithium, and total potassium. The holding time for inorganic chemicals will be 7 imited to 180 days.

\subsection{PHASE I SAMPLING LOCATIONS}

The sampling locations of the TSD Unit are shown in Figure 3. For Phase I. three sampling locations along the east side of the concrete pad were selected. One of these locations is at the northeast corner of the concrete slab (location 1). A second location is in the Separator Drain Sump (location 2). A third location is directly opposite the location of the southern treatment tank (location 3). Sampling location 3 is located slightly south of the concrete expansion joint that runs east to west near the middle of the pad. 
HNF-SD-ENV-AP-004, Rev. 0
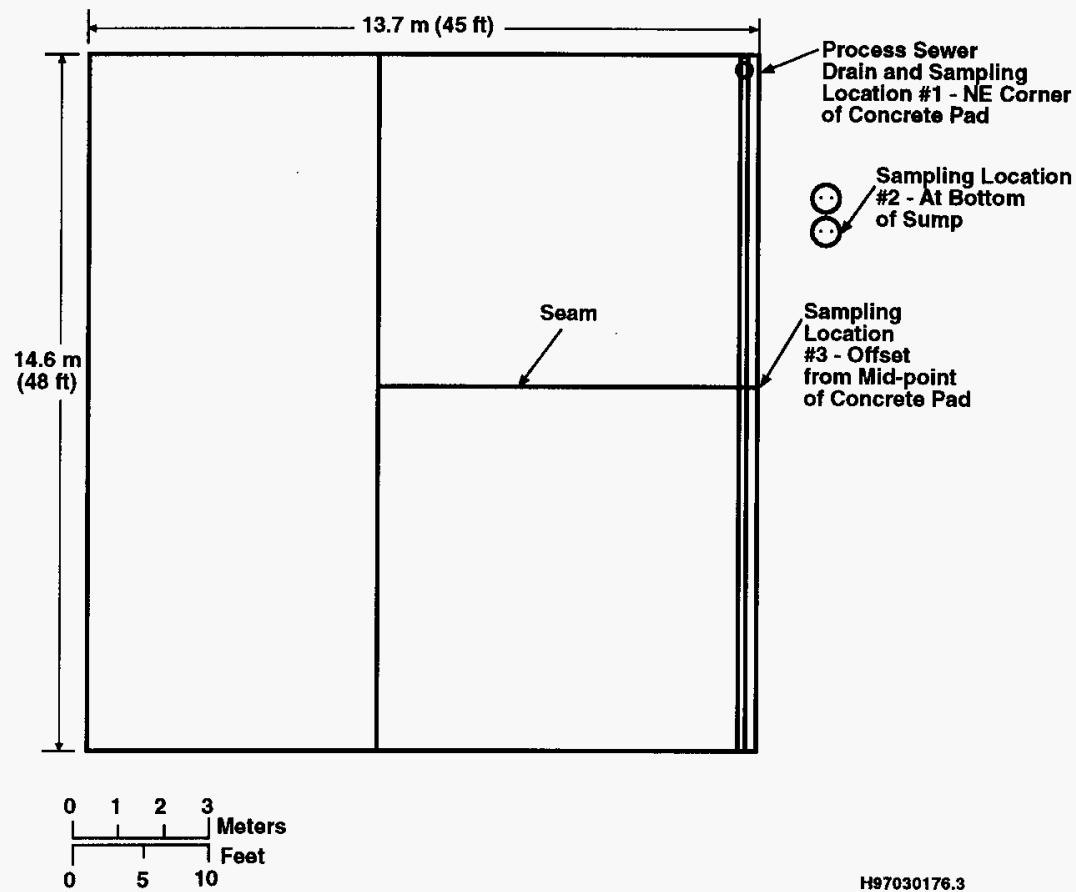

H97030176.3

DESCRIPTION OF SAMPLING LOCATIONS

Two sample locations are at the northeast corner of the concrete pad. One of these locations (location 1) is in the soil next to the process sewer drain and the second (location 2) is at the bottom of the separator drain sump. which is located approximately 3 meters ( 9 feet) south of the northeast corner. A third sample location (location 3 ) is near the mid-point of the concrete pad. which is directly south of the expansion joint that runs east/west. All samples will be collected at a sample interval from 15 centimeters ( 6 inches) to 46 centimeters (18 inches). Two duplicate soil samples will be collected: one at the northeast corner and the 10 other at sample location 3 . All material placed in the sample container will be
11 less than 12 millimeters $(0.5$ inches $)$ in diameter.

Figure 3. Soil Sampling Locations 
HNF-SD-ENV-AP-004, Rev. 0

\subsection{SOIL SAMPLING}

Soil samples will be collected at 3 locations. The sump drain sample (location 2) will be collected at the bottom of the sump from 15 to 46 centimeters (6 to 18 inches) in depth. The samples collected adjacent to the concrete pad (locations 1 and 3) will be 15 to 46 centimeters (6 to 18 inches) in depth from the soil surface. Field duplicate samples will be collected at sampling locations 1 and 3 (a total of 2) and will be co-located with samples 1 and 3 . Stainless steel hand tools, preferably an auger if soil and other conditions permit its use, will be used to collect the soil samples. If an auger is used, the sample material taken from the barrel of the auger will be placed in a stainless steel bowl and a representative sample will be taken from this material and placed in the sample container. Care will be taken to collect the representative sample over the full depth of the sample interval (approximately 30 centimeters). If an auger is used. the diameter of the soil sample (plug) will be from 75 to 125 millimeters depending on the nominal size of the auger. If hand tools are used (e.g., trowel or shovel). the material will be placed in a stainless steel bowl, and a representative soil sample will be collected from this material and placed in the sample container.

Clean equipment will be used for collecting each sample. If sampling equipment need decontamination, the equipment wi11 be decontaminated with an appropriate detergent and triple rinsed. All rinsate will be collected and properly disposed. All samples wi 11 be placed in new, EPA-approved, pre-cleaned polyethylene or plastic sample containers. The sample size wi 71 be specified on the Sample Authorization Form based on contractual arrangements with the analytical laboratory that will be used. It is assumed that a minimum sample size of 500 milligrams will be required. A minimum sample size of 200 milligrams will be required for analytical purposes or as specified on the Sample Authorization Form. If possible, each sample container will be filled unless otherwise specified on the Sample Authorization Form. Care will be taken not to place any large rocks in the sample container. No material with a diameter larger than 12 millimeters (approximately 0.5 inches) should be placed in the sample containers. If the soil sample contains numerous rocks that are greater than 12 millimeters, the soil sample shall be placed in a stainless steel bow? and the larger rocks removed before placing the sample in the sample container. If additional material is needed to fill the sample container, the material will be collected from the sides of the sample excavation.

Al1 samples will be labeled and sealed. Each sample will be assigned an unique sampie number by the Sample Management Group. The sample number wi 11 be entered into the Hanford Environmental Information System (HEIS). Additional information to be placed on the label will include but not be limited to the following: project name or identifier. name and signature of samplers, and the date and time that the sample was collected. A chain-of-custody form will be established to trace the sample from the time of collection through shipping and analysis. Information to be retained on the chain-of-custody form will include but not be limited to the following: project name, sample number, and the date, time, names, and signatures of all individuals involved in sample transfers. 
The sample labeling information and chain-of-custody record will be provided as part of the validation package. A record of all field activities will be maintained and documented in a field logbook in accordance with EII 1.5 requirements.

All samples will be sized in accordance with the analytical needs specified in Chapter 6.0. If requested, a split sample will be provided to Ecology for their analysis. All samples, including split samples and duplicate samples, are to be collected in accordance with EII 5.2, "Soil and Sediment Sampling" (see Chapter 5.0. Section 5.1). Co-located duplicate samples will be collected at soil sampling locations 1 and 3 . A summary of the soil samples to be collected is provided in Table 1.

Table 1. A Summary of Soil Sampling for Inorganics.

\begin{tabular}{|c|c|c|}
\hline Location & Sample Type & No. Samples \\
\hline 1 & $\begin{array}{l}\text { Soil sample collected at northeast } \\
\text { corner of pad, interval } 6 \text { to } 18 \text { inches }\end{array}$ & 1 \\
\hline 2 & $\begin{array}{l}\text { Soil sample collected at bottom of sump } \\
\text { drain (see Figure } 3 \text { ), interval } 6 \text { to } 18 \\
\text { inches }\end{array}$ & 1 \\
\hline 3 & $\begin{array}{l}\text { Soil sample collected near mid-point of } \\
\text { concrete pad, interval } 6 \text { to } 18 \text { inches }\end{array}$ & 1 \\
\hline 1 & $\begin{array}{l}\text { Duplicate sample at location } 1 \\
\text { (co-located) (QA/QC) }\end{array}$ & 1 \\
\hline 3 & $\begin{array}{l}\text { Duplicate sample at location } 3 \\
\text { (co-located) (QA/QC) }\end{array}$ & 1 \\
\hline
\end{tabular}

$Q A / Q C=$ quality assurance/quality control

\subsection{LABORATORY ANALYSIS}

The soil samples will be analyzed for total lithium, potassium, and sodium. The constituents of concern will be analyzed in accordance with SW-846. Method 6010, Inductively Coupled Plasma - Atomic Emission Spectroscopy (ICP) Metals (EPA 1986). Table 2 provides a summary of Contract Required Detection Limit (CRDL) and Laboratory Method Detection Limit (MDL) for soil using Method 6010. These values are compared to the range in natural concentrations found across the Hanford Site. Method 6010 is appropriate for this range of data. All samples will be prepared using Method 3050 (Acid Digestion). All analysis will be performed by an Ecologyaccredited laboratory under contract with the SMG. Care will be taken to limit the analysis to fine grain material (less than 2 millimeters). 
HNF-SD-ENV-AP-004, Rev. 0

1

2

3

4

5

6

7

Table 2. Detection Limits Using Method 6010.

\begin{tabular}{|c|c|c|c|}
\hline \multirow{2}{*}{ Analyte } & \multicolumn{2}{|c|}{ Detection Limits (mg $/ \mathrm{kg}$ ) } & \multirow{2}{*}{$\begin{array}{c}\text { Background Concentration. } \\
95 \% \text { UCL } \\
(\mathrm{mg} / \mathrm{kg})\end{array}$} \\
\hline & CRDL & MDL & \\
\hline Sodium & 1.4 & 2.2 & 1.390 \\
\hline Potassium & TBD & 158 & 3,090 \\
\hline Lithium & 0.2 & 0.98 & 37 \\
\hline
\end{tabular}

CRDL Contract Required Detection Level; "The minimum level of detection acceptable under the contractual statement of work" (WHC 1993)

MDL Method Detection Level: "The minimum concentration of a compound that can be measured and reported with $99 \%$ confidence that the value is above zero" (WHC 1993)

\subsection{QUALITY CONTROL}

All procurement and coordination of field sampling activities and laboratory services will be the responsibility of the SMG. The SMG will assign sample numbers, provide sampling specifications to both the field and analytical laboratory. maintain the responsibility for shipping and receiving samples, and provide a validated data package in accordance with the following guidelines.

\subsection{QUALITY CONTROL IN THE FIELD}

Field quality control includes the following:

- Co-located duplicate soil samples will be collected at sample locations 1 and 3 . These soil samples will be collected at a soil depth of 15 to 46 centimeters ( 6 to 18 inches).

Based on sample size, method of collection. media sampled. and constituents analyzed, the following applies:

- No trip blanks will be required because there will be no analysis for volatile organics

- One equipment blank will be required. This blank will be used to detect any contamination associated with the sampling equipment.

The equipment blank will be prepared using deionized water. Deionized water will be poured over or through the sampling device in the field and collected in a sample container. The collected sample will be returned to the SMG as a sample. 
All field samples will be collected in accordance with EII 5.2. "Soil and Sediment Sampling." All sample packing and shipping will be performed in accordance with EII 5.11. "Sample Packing and Shipping." All field cleaning and decontamination of soil sampling equipment will be performed in accordance with EII 5.4. "Field Cleaning and/or Decontamination." All field personnel wi 11 be trained in accordance with EII 1.7, "Qualifications and Training." No material larger than 12 millimeters will be collected in the field and placed in the sample containers.

\subsection{QUALITY CONTROL IN THE LABORATORY}

Ail soil samples will be analyzed for total sodium, lithium, and potassium. The constituents wi11 be analyzed in accordance with SW-846. Method 6010. for ICP metals. All soil samples and associated quality control samples will be analyzed in the same batch. Additionally, one laboratory control sample, one laboratory duplicate, one method blank, and one matrix spike will be prepared and processed as part of the sample batch. All laboratory quality control samples will be prepared using Method 3050 (Acid Digestion). All laboratory work will be performed by an Ecology-approved accredited laboratory and will be managed by SMG. All quality control criteria wi 11 be in accordance with Chapter 8.0. "Inorganic Data Validation Requirements". Data Validation Procedures for Chemical Analysis (WHC 1993). A copy of Chapter 8.0 has been provided as Appendix A for purposes of information.

\subsection{DATA VALIDATION}

Data validation will be performed to Leve? D standards for inorganic chemicals, as defined in Chapter 8.0. "Inorganic Data Validation Requirements" (WHC 1993). A description of the criteria that will be used for validation is provided as Appendix A. Level D validation for ICP metals consists of the following:

- Verification of required deliverables

- Verification of requested versus reported analyses

- Verification of lack of transcription errors

- Evaluation and quantification of results based on:

- analytical holding times

- matrix spikes

- laboratory control samples

- laboratory duplicates

- analytical method blanks

- matrix spike recoveries

- initial and continuing instrument calibrations

- calculational checks. 
The specific criteria for validation of inorganic metals analyses for both 6000 and 7000 Series Method is provided in Appendix A. As stated in condition V.13.B.e. "The results of all sampling shall be submitted to Ecology. These submittals shall include the raw analytical data, a summary of analytical results, a data validation package, and a narrative summary with conclusions."

\subsection{PATH FORWARD}

A discussion of the path forward that includes a description of tasks and planned deliverables is provided in this section.

\subsection{SCHEDULE}

Task 1: Revise and submit Sampling and Analysis Plan to Ecology for approval

Task 2: Within 30 days of Ecology's approval (See Task 1), collect field samples

Task 3: Within 45 days of completing Task 2. receive laboratory results

Task 4: Within 28 days of completing Task 3, complete validation package

Task 5: Within 14 days of completing Task 4. complete draft Data Evaluation Report (see Deliverables) and submit to Ecology for review and comment

Task 6: Prepare closure package for certification or prepare Phase II sampling and analysis plan.

\subsection{DELIVERABLES}

Deliverable 1: The sampling and analysis plan will be submitted to Ecology for approval

Deliverable 2: Provide Ecology with a copy of the validation data package including all supporting and raw data

Deliverable 3: A Data Evaluation Report will be prepared and submitted to Ecology. This report will include a summary of the raw data and analytical results, and a recommendation on future action

Deliverable 4: Prepare closure package for certification or a Phase II sampling and anaiysis plan. 
HNF-SD-ENV-AP-004, Rev. 0

10.0 REFERENCES

WAC 173-340, "The Model Toxics Control Act Cleanup Regulation," Washington Administrative Code, as amended.

DOE-RL. 1988. “3718-F Alkali Metal Treatment and Storage Area," Hanford Facility Dangerous Waste Part A Permit Application. DOE/RL-88-21.

Volume 3. Rev. 4. U.S. Department of Energy. Richland Operations Office. Richland, Washington.

D0E-RL, 1995a. The 3718-F A7kali Metal Treatment and Storage Facility Closure Plan, DOE/RL-91-35. Rev. 2, U.S. Department of Energy, Rich1and Operations Office. Richland. Washington.

DOE-RL. 1995b. Hanford Site Background: Part 1. Soi7 Background for Nonradioactive Ana7ytes. DOE/RL-92-24. Rev. 3. Volumes 1 and 2, U.S. Department of Energy. Richland Operations Office. Richland, Washington.

Ecology, 1996. Mode7 Toxics Control Act Cleanup Levels and Risk Calculations (CLARC II) Update. 1996. Washington State Department of Ecology, Lacy, Washington.

EPA, 1986. Test Methods for Evaluating Solid Waste: Physical/Chemical Methods. SW-846. U.S. Environmental Protection Agency, Washington. D.C.

IARC, 1996. "IARC Monographs on the Evaluation of the Carcinogenic Risk of Chemicals to Man." World Health Organization: International Agency for Research on Cancer (IARC) 1972-present. Geneva. Switzerland.

NIOSH. Registry of Toxic Effects of Chemical Substances. National Institute for Occupational Safety and Hea?th. Cincinnati. Ohio.

WHC. 1988, Environmental Investigations and Site Characterization Manual. WHC-CM-7-7. Westinghouse Hanford Company, Richland, Washington.

WHC, 1993, Data Validation Procedures for Chemical Analysis, WHC-SD-EN-SPA-002, Rev.2. Westinghouse Hanford Company, Richland, Washington. 
HNF-SD-ENV-AP-004, Rev. 0

APPENDIX A

DATA VALIDATION REQUIREMENTS FOR INORGANIC SAMPLES

APP A-j 
HNF-SD-ENV-AP-004, Rev. 0

This page intentionally left blank.

APP A- $\mathrm{A} i$ 
HNF-SD-ENV-AP-004, Rev. 0

1
APPENDIX A

DATA VALIDATION REQUIREMENTS FOR INORGANIC SAMPLES

APP A-1 
HNF-SD-ENV-AP-004, Rev. 0

This page intentionally left blank.

APP $\mathrm{A}-2$ 
HNF-SD-ENV-AP-004, REV. 0

\section{INORGANIC ANALYSIS DATA VALIDATION CHECKLIST}

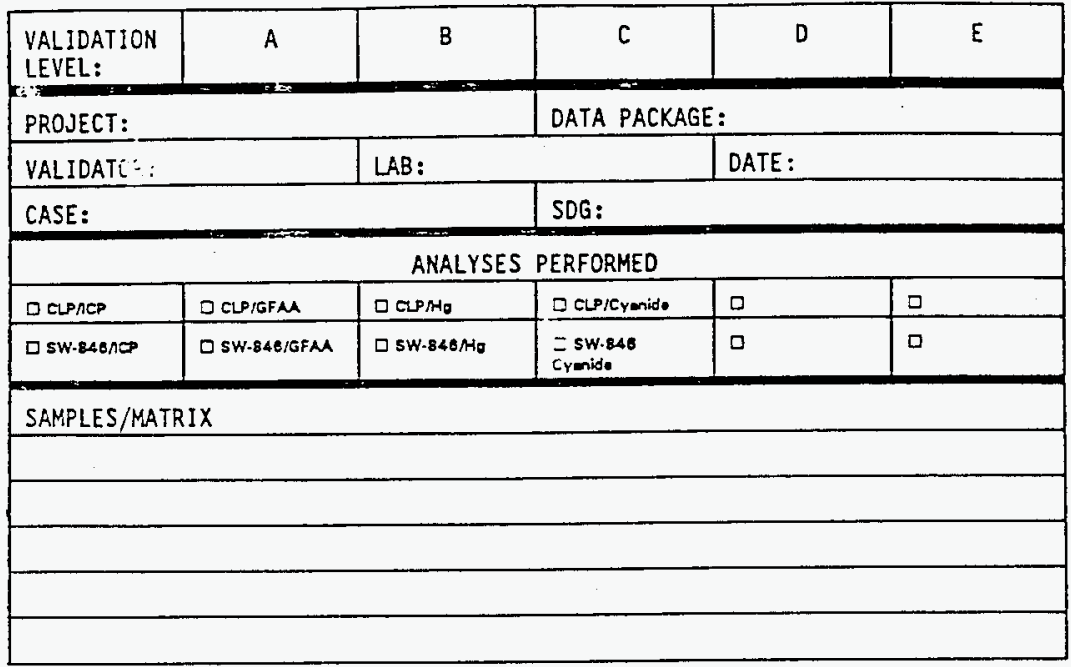

1. DATA PACKAGE COMPLETENESS AND CASE NARRATIVE

Is technical verification documentation present? . . . . . Yes No N/A

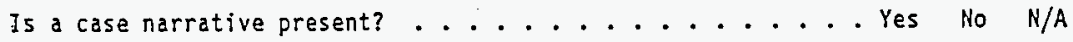
Comments:

2. HOLDING TIMES

Are sample holding times acceptable? .......... Yes No N/A Conments: 


\section{INORGANIC AKALYSIS DATA VALIDATION CHECKLIST}

\section{INSTRUMENT PERFORYANCE AND CALIBRATIONS}

Were initial calibrations performed on all instruments? . . . Yes No $N / A$

Are initial calibrations acceptable? .......... Yes No N/A

Are ICP interference checks a:zeptable? ......... Yes No N/A

Were ICV and CCV checks performed on all instruments? .... Yes No N/A Are ICV and CCV checks acceptable? .......... Yes No N/A Comments:

\section{BLANKS}

Were ICB and CCB checks performed for all applicable analyses? Yes No $N / A$ Are ICB and CCB resuits acceptable?.......... Yes No N/A Were preparation blanks analyzed?.......... Yes No $N / A$ Are preparation blank results acceptable? ......... Yes No $N / A$ Were field/trip blanks analyzed? ........... Yes No N/A Are field/trip blank results acceptable? ........ Yes No N/A Comments:

\section{ACCURACY}

Were spike samples analyzed? ............ Yes No N/A Are spike sample recoveries acceptable?.......... Yes No N/A Were laboratory control samples (LCS) analyzed? ....... Yes No N/A Are LCS recoveries acceptable? ............. Yes No N/A Comments: 


\section{INORGANIC ANALYSIS DATA YALIDATION CHECKLIST}

\section{PRECISION}

Were laboratory duplicates analyzed? .......... Yes No $N / A$ Are laboratory duplicate samples RPD values acceptable?... Yes No N/A Were ICP serial dilution samples analyzed? ........ Yes No $\mathrm{N} / \mathrm{A}$ Are ICP serial dilution 60 values acceptable? ....... Yes No N/A Are:field duplicate RPD values acceptable? ....... Yes No $N / A$ Are field split RPD values acceptable? ................. No $\mathrm{N} / \mathrm{A}$ Comments:

7. FURNACE AA QUALITY CONTROL

Were duplicate injections performed as required? . . . . Yes No N/A Are duplicate injection :RSD values acceptable? ...... . Yes No N/A Were analytical spikes performed as required?........ Yes No N/A Are analytical spike recoveries acceptable?......... Yes No N/A

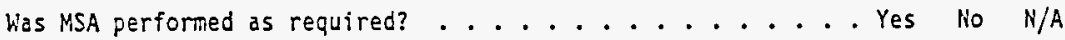
Are MSA results acceptable?....................... No N/A Comments:

\section{REPORTED RESULTS AND DETECTION LIHITS}

Are results reported for all requested analyses? . . . . . Yes No N/A Are all results supported in the raw data? ........ Yes No N/A Are results calculated properly? ............. Yes No N/A Do results meet the CRDLs? ............. Yes No N/A Comments: 
HNF-SD-ENV-AP-004, REV. 0

INORGANIC ANALYSIS DATA VALIDATION CHECKLIST

Comments (attach additional sheets as necessary): 
HOLDING TIME SUMMARY

\begin{tabular}{|c|c|c|c|c|c|c|c|}
\hline SDG: & & VALIDATO & & & DATE: & \multicolumn{2}{|c|}{ PAGE } \\
\hline \multicolumn{8}{|l|}{ COMMENTS: } \\
\hline $\begin{array}{l}\text { FIELD SAMPLE } \\
\text { ID }\end{array}$ & $\begin{array}{l}\text { ANALYSIS } \\
\text { IYPE }\end{array}$ & $\begin{array}{l}\text { DATE } \\
\text { SAMPLED }\end{array}$ & $\begin{array}{l}\text { DATE } \\
\text { PREPARED }\end{array}$ & $\begin{array}{l}\text { DATE } \\
\text { ANAL,YZED }\end{array}$ & $\begin{array}{l}\text { PREP. } \\
\text { HOLDING } \\
\text { TIME, DAYS }\end{array}$ & $\begin{array}{l}\text { ANALYSIS } \\
\text { HOLDING } \\
\text { TIME, DAYS }\end{array}$ & QUALIFIER \\
\hline & & & & & & & \\
\hline & & & & & & & \\
\hline & & & & & & & \\
\hline & & & & & & & \\
\hline & & & & & & & \\
\hline & & & & & & & \\
\hline & & & & & & & \\
\hline & & & & & & & \\
\hline & & & & & & & \\
\hline & & & & & & & \\
\hline & & & & & & & \\
\hline & & & & & & & \\
\hline & & & & & & & \\
\hline & & & & & & & \\
\hline & & & & & & & \\
\hline & & & & & & & \\
\hline & & & & & & & \\
\hline
\end{tabular}




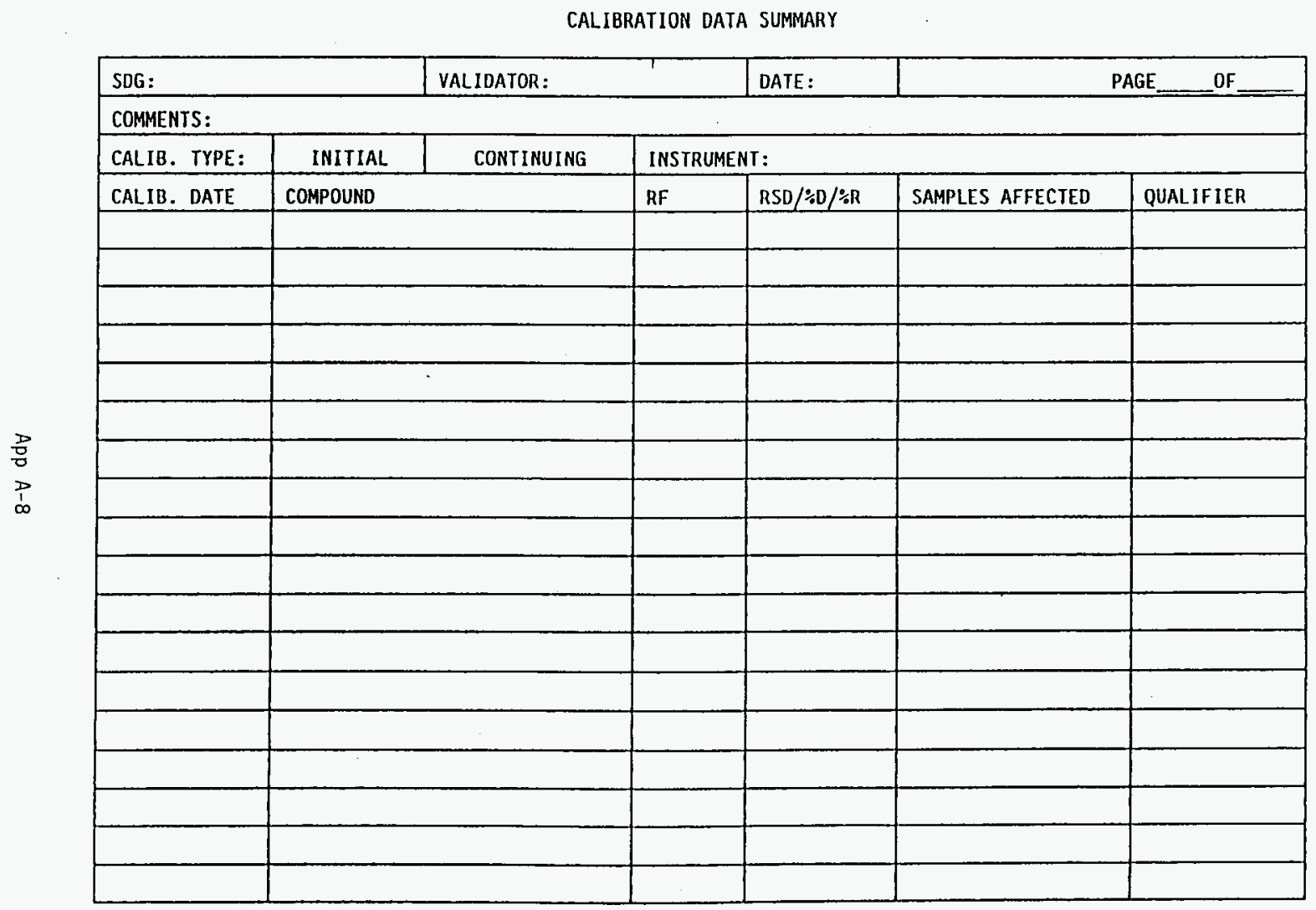




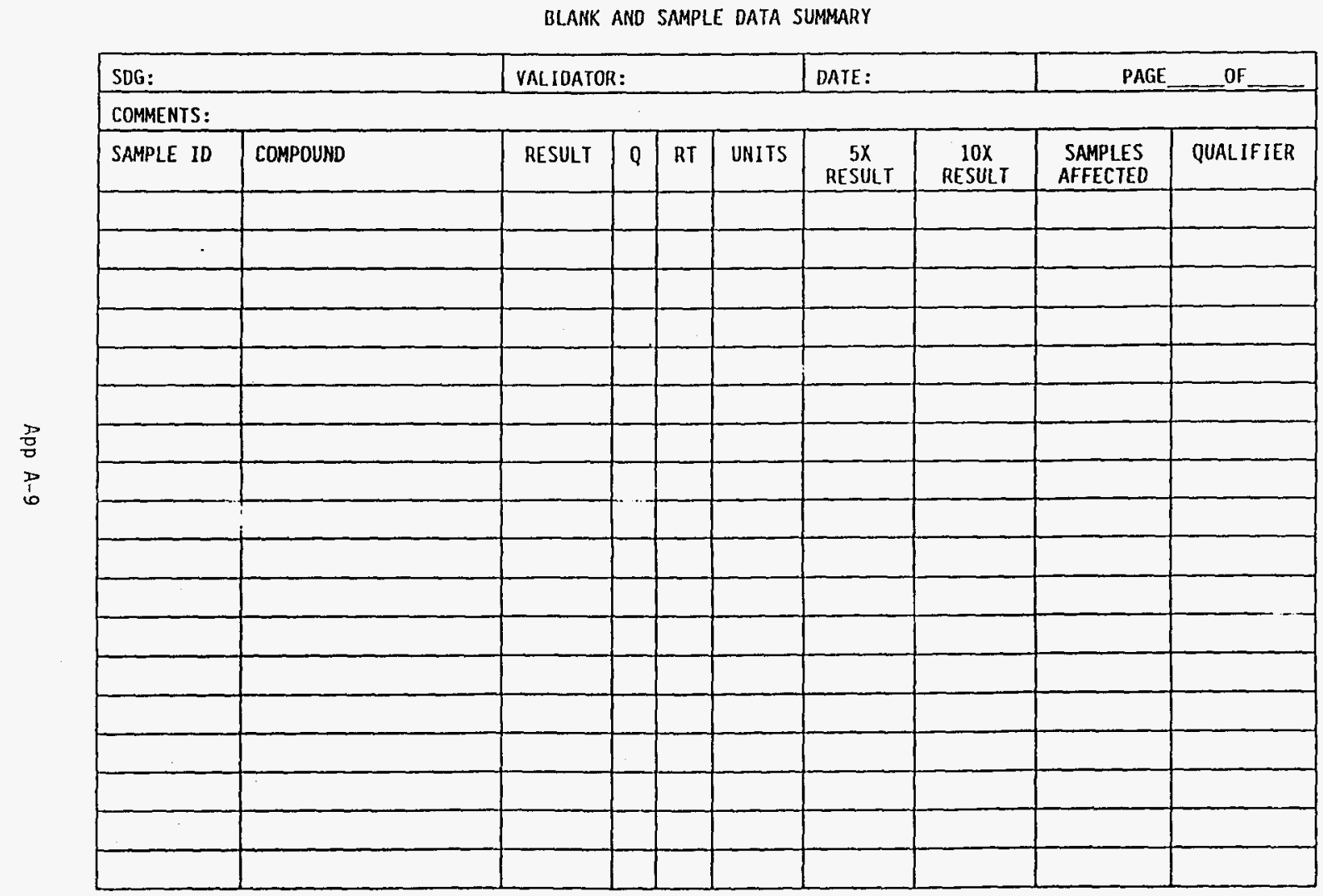


HNF-SD-ENV-AP-004, REV. 0

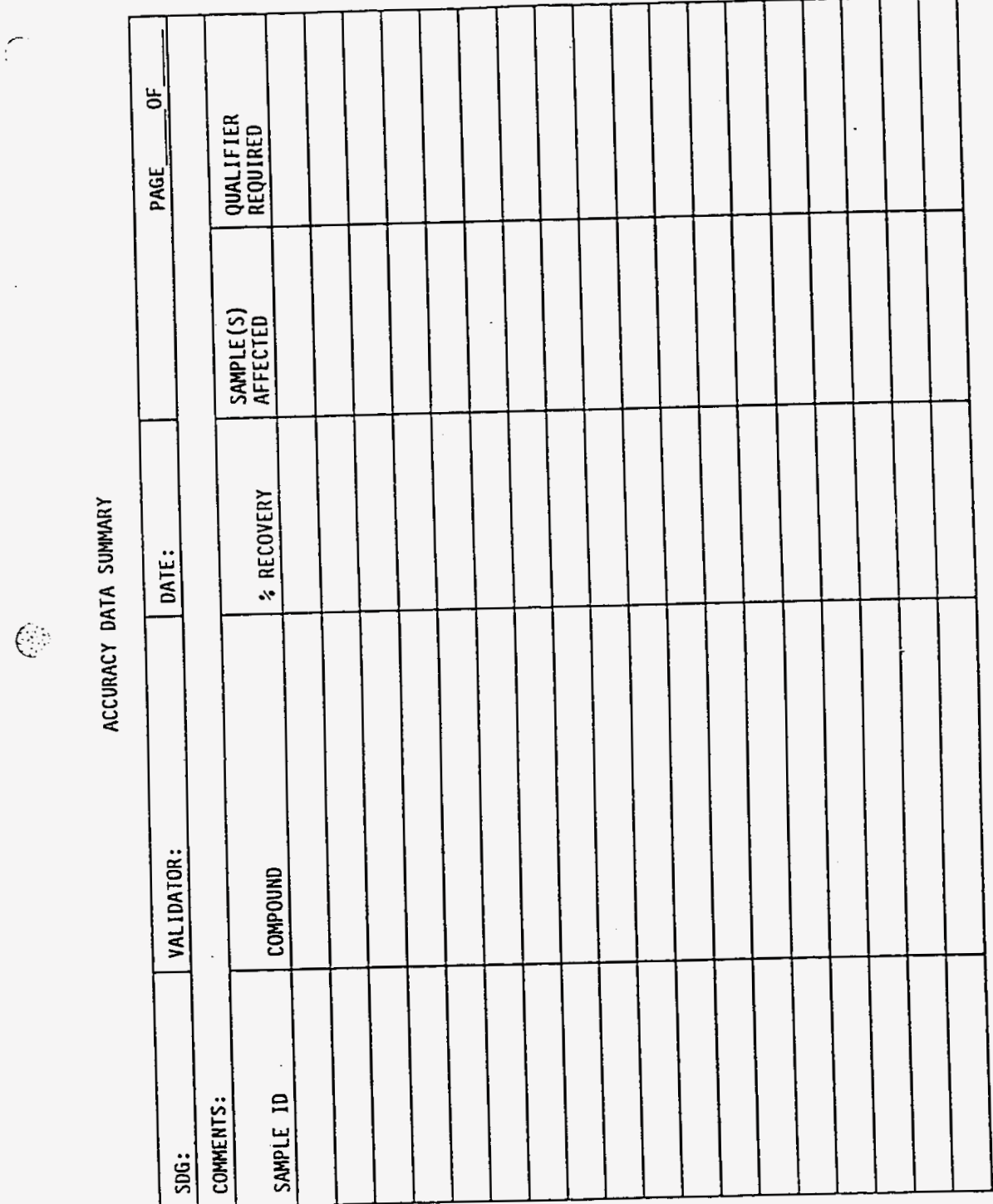

App A-10 
PRECISION DATA SUMMARY

\begin{tabular}{|c|c|c|c|c|c|c|}
\hline SOG: & VALIDATOR: & & DATE: & & & OF \\
\hline \multicolumn{7}{|l|}{ COMMENTS: } \\
\hline \multicolumn{2}{|l|}{ COMPOUND } & SAMPLE ID: & SAMPLE ID: & RPD & SAMPLES AFFECTED & QUALIFIER \\
\hline & & & & & & \\
\hline & & & & & & \\
\hline & & & & & & \\
\hline & & & & & & \\
\hline & & & & & & \\
\hline & & & & & & \\
\hline & & & & & & \\
\hline & & & & & & \\
\hline & & & & & & \\
\hline & & & & & & \\
\hline & & & & & & \\
\hline & & & & & & \\
\hline & & & & & & \\
\hline & & & & & & \\
\hline & & & & & & \\
\hline & & & & & & \\
\hline & & & & & & \\
\hline & & & & & & \\
\hline
\end{tabular}


HNF-SD-ENV-AP-004, REV. 0

\section{CALCULATION SUMMARY}

\begin{tabular}{|l|l|l|l}
\hline SDG: & REVIEWER: & DATE: & PAGE_OF \\
\hline
\end{tabular}

COMMENTS:

.

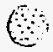

App A-12 
HNF-SD-ENV-AP-004, REV. 0

DATA QUALIFICATION SUMMARY

\begin{tabular}{|c|c|c|c|}
\hline SDG: & VALIDATOR: & DATE: & PAGE___ OF \\
\hline \multicolumn{4}{|c|}{ COMMENTS: } \\
\hline COMPOUND & QUALIFIER & SAMPLES AFFECTED & REASON \\
\hline & & & \\
\hline & & & \\
\hline & & & \\
\hline & & & \\
\hline & & & \\
\hline & & & \\
\hline & & & \\
\hline & & & \\
\hline & & & \\
\hline & & & \\
\hline & & & \\
\hline & & & \\
\hline & & & \\
\hline & & & \\
\hline & & & \\
\hline & & & \\
\hline & & & \\
\hline & & & \\
\hline & & & \\
\hline & & & \\
\hline & & & \\
\hline & & & \\
\hline & & & \\
\hline & & & \\
\hline & & & \\
\hline & & & \\
\hline & & & \\
\hline
\end{tabular}

App A-13 
HNF-SD-ENV-AP-004, REV. 0

TELEPHONE CONTACT SUMMARY

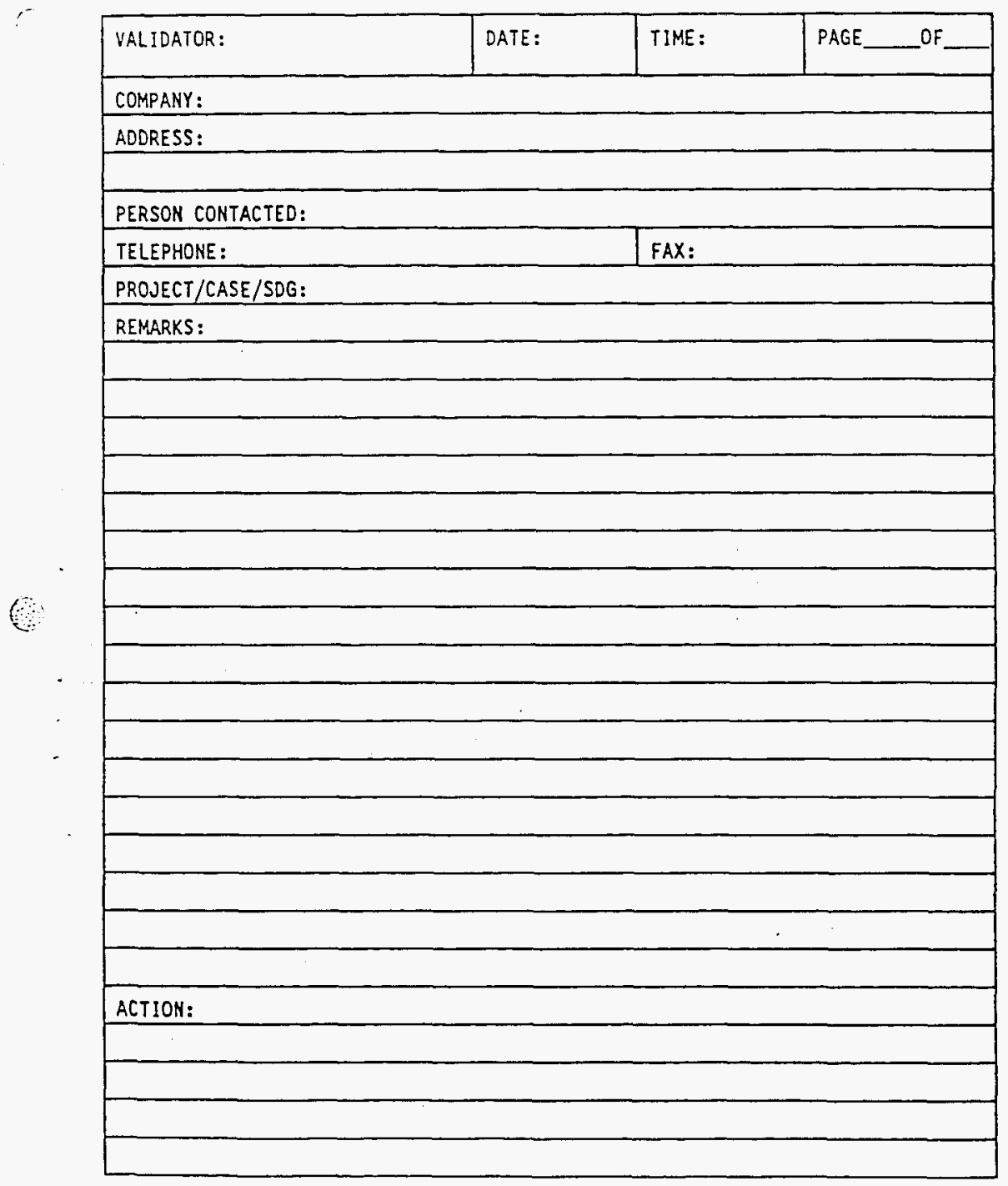

App A-14 
HNF-SD-ENV-AP-004, REV. 0

Matrix Spike Recovery $(\% R)$

$$
\frac{S S R-S R}{S A} \times 100 \text { where, }
$$

$$
\begin{aligned}
& \text { SSR }=\text { spike sample result } \\
& \text { SR }=\text { sample result } \\
& S A=\text { spike added }
\end{aligned}
$$

\section{Relative Percent Difference (RPD)}

MS/MSD analysis RPD:

$$
R P D=\frac{|M S R-M S D R|}{(M S R+M S D R) / 2} \times 100 \text { where, }
$$

$$
M S R=\text { matrix spike recovery }
$$

$M S D R=$ matrix spike duplicate recovery

Duplicate sample analysis RPD:

$$
R P D=\frac{|S-D|}{(S+D) / 2} \times 100 \text { where, }
$$

$S=$ sample concentration

D = duplicate sample concentration

\section{Relative Standard Deviation ( $\%$ RSD)}

$$
\because R S D=\frac{S D}{\bar{x}} \times 100 \text { where, }
$$

SO = Standard deviation of the initial five response factors per compound, calculated as

$$
\sqrt{\sum_{i=1}^{n} \frac{\left(x_{i}-\bar{x}\right)^{2}}{n-1}} \text { and }
$$

$\bar{x} \quad=$ mean of initial five response factors 
Relative Response Factor (RRF) (volatiles and semivolatiles)

$$
R R F=\frac{A_{x}}{A_{i}} \times \frac{C_{i x}}{C_{x}} \text { where, }
$$

$$
\begin{aligned}
A_{x}= & \text { area of the characteristic ion measured } \\
A_{i}= & \text { area of the characteristic ion measured for the associated } \\
\text { internal standard } & \\
C_{x}= & \text { concentration (in } n g \text { for volatiles and } n g / \mu l \text { for } \\
C_{i}= & \text { semivolatiles) of the characteristic compound of interest } \\
& \text { concentration (in } n g \text { for volatiles and } n g / \mu \text { for } \\
& \text { standard } \\
& \text { stales) of the characteristic associated interval }
\end{aligned}
$$

Percent Difference (\%D, volatile and semivolatile RRF values)

$$
\div D=\left[\left(R R F_{i}-R R F_{0}\right) / R R F_{i}\right] \times 100 \text { where, }
$$

$R R F_{i}=$ the average RRF from the initial calibration

$R R F_{e}=$ the RRF value from the continuing calibration

Surrogate Recoveries $(\% R)$

$$
\because R=\left(Q_{d} / Q_{d}\right) \times 100 \text { where, }
$$

$Q_{d} \quad=$ quantity of surrogate determined from the analysis

$Q_{\text {. }}$ = quantity of surrogate added to the sample

Results Calculations (volatile analysis)

- Water Samples, $\mu g / \mathrm{L}$

$$
\frac{\left(A_{x}\right)\left(I_{0}\right)\left(D_{1}\right)}{\left(A_{\text {. }}\right)(R R F)\left(V_{0}\right)} \text { where, }
$$

\footnotetext{
$A_{x}=$ area of the quantitation ion (EICP) for the compound measured

$A_{i s}=$ area of the quantitation ion (EICP) for the specified internal standard

l. = amount of internal standard added in nanograms (ng)
} 

RRF = relative response factor from the ambient temperature purge of the calibration standard
$V_{0}=$ volume of water purged in miliiliters (mL)
$D_{i}=$ dilution factor. The dilution factor for the analysis of water samples for volatiles is defined as the ratio of the number of $\mathrm{mL}$ of water purged $\left(V_{0}\right)$ to the number of $\mathrm{mL}$ of the original sample used for purging. For example, if 2.5 $\mathrm{mL}$ of sample is diluted to $5.0 \mathrm{~mL}$ with reagent water and purged, $D_{f}=5.0 \mathrm{~mL} / 2.5 \mathrm{~mL}=2.0$. If no dilution is performed, $D_{1}=1.0$.

- Soil/sediment samples, low level, $\mu g / \mathrm{Kg}$

$$
\frac{\left(A_{x}\right)\left(I_{2}\right)}{\left(A_{10}\right)(R R F)\left(W_{0}\right)(D)} \text { where, }
$$

Ax. I., $A_{\text {in, }}$ RRF are as given for water samples above,

$D=(100$ - imoisture $) / 100$

$W_{1}$ = weight of sample added to the purge tube in grams $(g)$.

- Soil/sediment samples, medium level, $\mu \mathrm{g} / \mathrm{Kg}$

$$
\frac{\left(A_{0}\right)\left(I_{0}\right)(1000)\left(D_{1}\right)}{\left(A_{i}\right)(R R F)\left(V_{.}\right)\left(W_{2}\right)(D)} \text {, where }
$$

$A_{x}, I_{1}, A_{\text {in }}$, RRF are as given for water samples above

$V_{t}=$ total volume of methanol extract in $\mathrm{mL}$. Note: this volume is typically $10.0 \mathrm{~mL}$, even though only $1.0 \mathrm{~mL}$ is transferred to a vial for storage as specified in the sow

$v_{0}=$ volume of the aliquot of methanol extract in $\mu \mathrm{L}$ added to reagent water for purging

$W_{0}=$ weight of soil extracted, in grams

$D^{*} \quad=$ same as given for low level soils above

$D_{f}=$ Dilution factor. The dilution factor for the analysis of soil/sediment samples for volatiles by the medium level method is defined as the ratio of the number of nanogram of methanol added to the reagent water from purging, (i.e. $V_{n}$, above), to the number of nanogram of methanol extract of the sample contained in volume $V_{\text {. }}$. The dilution factor is equal to 1.0 in all cases other than those requiring dilution of the methanol extract. The factor of 1,000 in the numerator converts the value of $V_{t}$ from $\mathrm{mL}$ to $\mu \mathrm{L}$. 
Result Calculations (semivolatile analysis)

- Water samples, $\mu g / L$

$$
\frac{\left(A_{x}\right)\left(I_{e}\right)\left(V_{1}\right)\left(D_{f}\right)}{\left(A_{i \infty}\right)(R R F)\left(V_{0}\right)\left(V_{i}\right)} \text { where, }
$$

$A_{x}=$ area of the quantitation ion (EICP) for the compound measured

$A_{i,}=$ area of the quantitation ion (EICP) for the specified internal standard

$I_{1}=$ amount of internal standard added in nanograms ( $\mathrm{ng}$ )

$V_{0}=$ volume of water extracted in milliliters $(\mathrm{mL})$

$V_{i}=$ volume of extract injected in microliters $(\mu \mathrm{L})$

$V_{i}=$ volume of concentrated extract in $\mu \mathrm{L}$

- $R R F=$ relative response factor from the daily calibration standard

$D_{f}=$ dilution factor. The dilution factor for analysis of water samples for semivolatiles is defined as follows:

$\mu L$ of most conc. extracted used for dilution $+\mu \mathrm{L}$ clean solvent $\mu L$ most conc. extract used to make dilution

If no dilution is performed, $D_{t}=1.0$

- Soil samples, $\mu g / \mathrm{Kg}$

$$
\frac{\left(A_{x}\right)\left(I_{0}\right)\left(V_{i}\right)\left(D_{i}\right)}{\left(A_{i p}(R R F)\left(V_{i}\right)\left(W_{p}\right)(D)\right.} \text { where, }
$$

$A_{x}, I_{1}, A_{i 0}, R R F, V_{i}, V_{i}, D_{1}$ are as given for water samples above

$0=(100$ - imoisture $) / 100$

$W_{0}=$ weight of sample extracted in grams $(g)$.

\section{Resolution (pesticide analysis)}

Resolution $=\left(P_{v} / P_{h}\right) \times 100$ where,

$P_{v}=$ the peak height of the valley of the larger peak

$P_{h}$ = the peak height of the smaller peak being resolved. 
Percent Difference ( $\%$, pesticides/PCB analys is)

$$
\begin{aligned}
\because D= & \left(R T_{i}-R T_{0}\right) / R T_{i} \times 100 \text { where, } \\
R T_{i}= & \text { the absolute retention time of } D B C \text { in the initial standard } \\
& (E V A L A) \text { mixture } \\
R T_{1}= & \begin{array}{l}
\text { the absolute retention time of } \mathrm{DBC} \text { in the sample and } \\
\text { subsequent standards }
\end{array}
\end{aligned}
$$

Percent Breakdown (pesticides/PCB analysis)

$$
\because \text { Breakdown }=\frac{\text { Totol Degrodation Peak Area }}{\text { Totol Peak Area }} \times 100 \text { where, } \quad \text { D-16 }
$$

total degradation peak area = the sum of the peak area for DDE and DDD or endrin aldehyde and endrin ketone

total peak area = sum of all associated peak areas for DDE, DDD and DDT or endrin, endrin aidehyde an endrin ketone.

DBC Retention Time Percent Difference (pesticide/PCB analysis)

$$
\therefore D=\frac{R T_{i}-R T_{i}}{R T_{i}} \times 100 \text { where, }
$$

$R T_{i}=$ Absolute retention time of dibutylchlorendate in the initial standard (Evaluation Standard Mix A)

$R T_{2}=$ Absolute retention time of dibutyichlorendate in the subsequent standard and sample analyses 


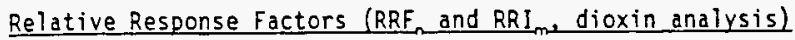

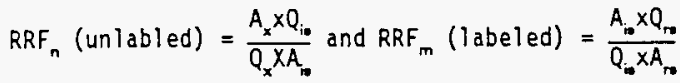

$$
\begin{aligned}
& R S D=\frac{R R F_{m}}{R R F_{\delta}} \text { where, } \\
& \text { where, }
\end{aligned}
$$

$$
\begin{aligned}
& A_{x}=\text { sum of the integrated ion abundances of the quantitation } \\
& \text { ions for the uniabeled PCDDs/PCDFs } \\
& A_{i}=\text { sums of the integrated ion abundances of the quantitation } \\
& \text { ions for the labeled internal standards } \\
& A_{r}=\text { sum of the integrated ion abundances of the quantitation } \\
& \text { ions for the labeled recovery standards } \\
& \mathrm{Q}_{\mathrm{i}}=\text { quantity of the internal standard injected (picograms pg) } \\
& Q_{r} \quad=\text { quantity of the recovery standard injected (pg) } \\
& Q_{x}=\text { quantity of the unlabeled PCDD/PCDF analyte injected ( } p g \text { ) } \\
& R R F_{m}=\text { mean of the five response factors for the particular } \\
& \text { PCDD/PCDF analyte } \\
& R R F_{s}=\text { standard deviation of the five response factors for the } \\
& \text { particular PCDD/PCDF analyte }
\end{aligned}
$$

\section{Results Calculations (inoraanics analysis)}

- Water, $\mu \mathrm{g} / \mathrm{L}=\mathrm{C} \times \mathrm{D}$ where,

$$
\begin{aligned}
& C=\text { concentration, } \mu \mathrm{g} / \mathrm{L} \text { from calibration curve } \\
& D=\text { dilution factor (if any) }
\end{aligned}
$$

- Soit, $\mathrm{mg} / \mathrm{Kg}=(C \times D) /(W \times S)$ where,

$$
\begin{aligned}
& C=\text { concentration, } \mathrm{mg} / \mathrm{L} \text { from calibration curve } \\
& D=\text { volume in } \mathrm{mL} \text { of final extract volume } \\
& W=\text { weight of sample in grams } \\
& S=(100-\text { imoisture }) / 100
\end{aligned}
$$

Serial Dilution ( $\% D$, inorganics analysis)

$$
\begin{aligned}
& \% D=[|T-S| / I] \times 100 \text { where } \\
& I=\text { analyte concentration before dilution } \\
& S=\text { serial dilution analyte concentrations }
\end{aligned}
$$


HNF-SD-ENV-AP-004, Rev. 0

2

3

4

5

6

7

8

9

10

11

12

13

14

15

16

17

18

19

20

21

22

23

24

25

26

27

28

29

30

31

32

33

34

35

36

37

38

39

40

41

42

43

44

45
DISTRIBUTION

Number of coptes

OFFSITE

3

Washington State Department of Ecology

Nuclear Waste Program

1315 west 4th

Kennewick, Washington 99336-6018

C. D. Stuart

J. J. Wallace

J. K. Bartz

ONSITE

2

U.S. Department of Energy.

Richland Operations office

* E. M. Mattlin

A5-15

* D. H. Chapin

R3-79

3

B\&w Hanford Company

* T. A. Dillhoff

N2-57

* K. A. Hadley

R3-56

* C. D. Sorensen

R3-56

4

Elvor Daniel Hanford. Inc.

D. B. Klos

N2 -51

* C. G. Mattson

$\mathrm{N} 1-26$

$\mathrm{H} 6-23$

* S. M. Price

* F. A. Ruck III

H6-23

4

Lockheed Mart in Services. Inc.

* Central files

Document Processing Center

A3-88

Unclassified Document Control

A3-94

A4-65

EDMC/AR 
HNF-SD-ENV-AP-004, Rev. 0

\section{DISTRIBUTION (cont)}

2

3 Number of copies

4

5

6

7

8

9

10

11

12

13

14

15

16

17

ONSITE

4

2

Rust Federal Services of Hanford. Inc.

R. C. Bowman

$\mathrm{H} 6-24$

* R. H. Engelman

H6-26

* J. C. Sonnichsen

$\mathrm{H} 6-24$

3. G. Paete]

E6-06

Rust Federal Services Northwest

D. L. Edwards

H1-12

K. J. Young

$\mathrm{H} 1-12$ 


\section{B\&W Hanford Co.}

a McDermott company

Io

Mr. D. B. Klos, Deputy Director

N2-36

FFTF Standby Project Office, FQH

\begin{tabular}{|c|c|c|}
\hline From & E. F. Loika, Director, FFTF Project $\sum 1$ twhe & $\begin{array}{l}\text { File No. Or Ref.: } \\
\text { BWHC-9754727 }\end{array}$ \\
\hline subj & $\begin{array}{l}\text { ISSUANCE OF SOIL SAMPLING AND ANALYSIS PLAN FOR THE 3718-F } \\
\text { ALKALI METAL TREATMENT AND STORAGE FACILITY CLOSURE } \\
\text { ACTIVITIES, HFN-SD-ENV-AP-004, REV.0, MAY } 1997\end{array}$ & Date: \\
\hline
\end{tabular}

The 3718-F Alkali Metal Treatment and Storage Facility Closure Plan was included in Revision 3 of the Hanford Facility Resource Conservation and Recovery Act of 1976 Permit in November 1996. Included at that time was a unit-specific condition that required the collection and analysis of soil samples. This condition (Permit Condition V.13.B.b) states, "the Department shall be provided, for review and approval, a soil sampling and analys is plan at least 30 days prior to initiating actual sampling. Such a plan shall include a schedule for conducting sampling events. The analytical results of the sampling event will be used to determine if corrective action will be requitred to close the 3718-F Alkali Metal Treatment and Storage Facility."

In response to this requirement, the subject soil sampling and analysis plan was submitted to the Washington State Department of Ecology for review and comment at the Project Managers* Meeting held March 13, 1997. Approval of the soil sampling and analysis plan was received on April 24, 1997.

The subject $\mathrm{plan}$ was prepared by Rust Federal Services of Hanford, Inc. (RFSH), Environmental Services Department for B\&W Hanford Company (BWHC).

Should you have any questions or comments, please contact Mr. T. A. Dillhoff (BWHC) of my staff at (509) 376-0441 or Mr. J. C. Sonnichsen (RFSH) at (509) $376-9956$.

sms

Attachment 
BWHC-9754727

\section{ATTACHMENT}

HFN-SD-ENV-AP-004

"Soil Sampling and Analysis Plan for the

3718-F Alkal i Metal Treatment and Storage Facility

Closure Activities"

Consisting of 47 pages,

including cover page 


\section{CORRESPONDENCE DISTRIBUTION COVERSHEET}

Author

T. A. Dillhoff, BWHC
Addressee

D. B. Klos, FDH
Correspondence No.

BWHC-9754727

Subject: ISSUANCE OF SOIL SAMPLING AND ANALYSIS PLAN FOR THE 3718-F ALKALI METAL TREATMENT AND STORAGE FACILITY CLOSURE ACTIVITIES, HFN-SD-ENV-AP-004, REV. O, MAY 1997

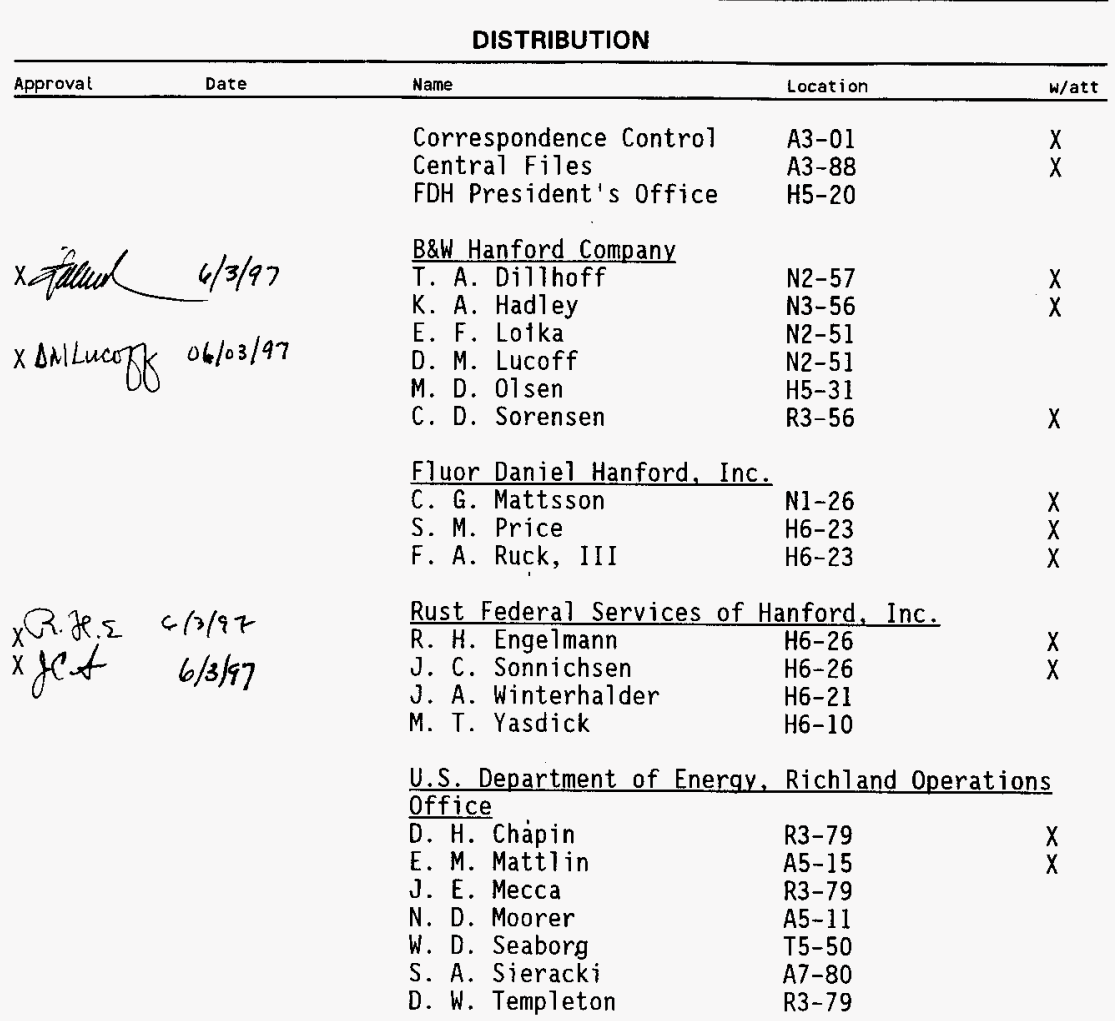

